\title{
Science as a common language for contribution to sustainability and peace
}

\author{
Fumiko Kasuga' ${ }^{1}$ (1)
}

Received: 30 September 2020 / Accepted: 30 April 2021 / Published online: 12 May 2021

(C) The Author(s), under exclusive licence to Springer Japan KK, part of Springer Nature 2021

\begin{abstract}
There are many reasons and background factors for conflict including differences in political and social beliefs and values. Wars have also been a threat to the environment and sustainability. Inequality and disparity are more apparent in the world due to COVID-19. Now, we also need to consider environmental changes caused by human activities as climate extremes might cause new conflicts. More studies are needed for a comprehensive understanding of holistic views on challenges at the interfaces of peace and sustainability that inherently involve inter- and trans-disciplinary collaboration among cohorts of communities of practice. Collaborative scientific research on these interfaces is being conducted under the Future Earth Programme, and many others. In this commentary, I posit that science offers an effective pathway and a common platform for engagement and interactions aimed at the nexus of sustainability and peace under global changes.
\end{abstract}

Keywords Science $\cdot$ Ethics $\cdot$ Peace $\cdot$ Sustainability $\cdot$ Future Earth

\section{Introduction}

The focus of the last year's International Day of Peace was "Shaping Peace Together." UN Secretary General António Guterres alerted that the COVID-19 pandemic is a leading risk to peace (UN News 2020). Inequality and disparity are becoming more apparent worldwide due to the pandemic, and segmentation of society often causes new conflicts. Climate change is another driver of conflicts as it threatens our lives, food, water, energy supply, and homes. A set of sustainable development goals (SDGs) aims to be an anchor for the world toward sustainability; however, the achievement of the SDGs could be slowed down by the COVID-19 pandemic. Science and technology have been developed in human history to obtain and secure a safe and comfortable living environment. Currently, scientific knowledge and innovative solutions are needed to address the global threats

Handled by Ayyoob Sharifi, Hiroshima University IDEC Higashi Hiroshima, Japan.

Fumiko Kasuga

fumiko.kasuga@futureearth.org

1 National Institute for Environmental Studies/Future Earth, 16-2 Onogawa, Tsukuba-City, Ibaraki 305-8506, Japan to our lives. However, history has also proven that science and technology have created new sources of conflict and tools for fighting. This paper discusses what science can do and how scientists should behave in order to shape peace.

\section{New conflict with COVID-19 and social inequality}

"Beyond war zones, the pandemic is highlighting and exploiting inequalities of all kinds, setting communities and countries against each other," UN Secretary General Mr. Guterres expressed his serious concerns prior to the International Day of Peace this year (UN News 2020). COVID19 has brought socio-economic inequalities in communities globally as well as significant restrictions on people's freedom, which are justified by the need to save lives (Zinn 2020). Furthermore, some racial and ethnic minority groups are affected by COVID-19 more than other communities due to multiple, complex reasons (US CDC 2020). Linked with the global movement of anti-racism protests with the Black Lives Matter (BLM), the disproportionate rates of COVID19 deaths have drawn attention to unfairness and social injustices, which can be sources of anger. Scientists have been analyzing epidemiological data and background factors 
from various perspectives. As we still have limited information regarding SARS-CoV-2 and COVID-19, more scientific efforts should be focused on identifying physical and social causes to address this issue. Furthermore, Asayama et al. (2020) encouraged sustainability scientists to focus more on human society and its inequalities by suggesting three areas to focus on: (1) health and wellbeing, (2) moral engagement through empathy, and (3) science of loss for managing grief.

\section{Climate change and new conflict}

Countries and populations with lower incomes are more vulnerable to climate change and related disasters (Future Earth and Earth League 2019). Low-income or medium-lowincome countries have a weaker capacity to cope with and adapt to the risks of climate change, and they are less resilient in terms of their ability to recover from disasters. With the predicted increase in climate disasters, people in these countries will experience more difficulties in being freed from poverty. An inability to safeguard land, crops, and water from climate hazards will lead to political instability within these countries as well as the larger regions where they belong. Additionally, climate change has induced forced displacement. In 2018, weather-related disasters caused an in-country migration of 16.1 million people globally (IDMC 2019). If people migrate outside their countries, it may become a cause of a new conflict.

An exponential growth in the scale and pace of human activities is regarded as a major driver of exponential change in various elements in the environment, expressed as Great Acceleration (Steffen et al. 2015). Continuous observation to understand rapid changes in both the environment and society and more accurate prediction of future changes based on obtained data will help communities prepare for upcoming disasters and reduce damage. Practical knowledge to reduce avoidable harm should be transferred to vulnerable countries and communities, translated into mother languages, and utilized effectively.

\section{Science for political justice}

Science and technology have been promoted in human history and have contributed to human health and wellbeing. Under the new and urgent threats mentioned above, scientific knowledge and innovative solutions are needed more to save lives. However, we find in our history that science and technology have also created new sources of conflict and new weapons. It should be noted that many renowned scientists, including Nobel Laureates and medical doctors, have committed to creating lethal weapons, with high sense of mission and nationalism. They remain proud to serve their countries' pursuit of political justice, both for civilians and national armies, e.g. in the Manhattan Project and Detachment 731 of the Imperial Japanese Army.

The rapid development of the latest technologies, including artificial intelligence (AI), digital technologies, brain research, gene editing technology, reproductive medicine, and others, may become sources of new conflict if appropriate rules, reviews, and full discussion systems are not developed.

\section{Science and dual use of concerns}

A sarin attack by a religious cult in Japan in 1994 and 1995, the postal distribution of anthrax bacilli following the September 11 terrorist attack, and even recent research on highly virulent avian $\mathrm{H} 5 \mathrm{~N} 1$ influenza viruses have caused biosecurity and chemical security concerns worldwide. In parallel with conventions, laws, regulations, and rules at international, national, and organizational levels to prevent intentional, malicious use of pathogens and chemical and biological weapons, scientific communities have been making efforts to self-manage such concerns. Then Inter-Academy Panel (current InterAcademy Partnership) issued the "IAP Statement on Biosecurity" (IAP 2005), with support from member academies, including Science Council of Japan. Following discussions among Japanese scientists and the Ministries of Foreign Affairs, Defense, and Health, Labor, and Welfare of Japan, Science Council of Japan issued a "Report on Dual Use Issue of Science and Technology (in Japanese)" (Science Council of Japan 2012) and revised "Code of Conducts for Scientists (in Japanese)" (Science Council of Japan 2013). It is noted in the report that any kind of science has the possibility of being misused, regardless of the original intention for human welfare. To address the "dual use dilemma," security concerns on science and technology must be considered simultaneously with research freedom, public health needs, and innovation. Professor Hiroshi Yoshikura, Chairperson of the Committee in Science Council of Japan, which developed above report, introduced a framework for biosecurity comprised of architecture, ownership, and regulability (Yoshikura, 2013).

\section{Conclusion—shaping peace together}

With the COVID-19 pandemic, people have recognized their responsibility not only for individual health but also for the health of others (Zinn 2020). People have to work together more closely than ever to cope with global health and climate crises as well as to achieve peace and sustainability. Science should provide an analysis of the past and current status and predict the future of the environment and society 
with the best available information. Science, both social and natural, together with the humanities, can foster an understanding of human psychology, social mechanisms, political tension, and the effect of external powers, such as climate change and pandemics, on the current tension and balance in the society. Scientists should also put forward efforts to make useful and customized translations of knowledge widely available. These efforts can enable decision-making, at various levels of governance and by various players in societies, that is based on the highest quality of evidence at the time. However, scientists should carefully observe how the evidence they have provided is used by decision-makers. Scientists should speak out if an incorrect interpretation of scientific evidence is made.

Science can serve as a common language in diplomacy, similar to arts and sports, even in conflict situations. Another key role science can play is providing multiple perspectives on an event, adding diverse values and views that could deliver additional opportunities to solve serious conflicts. It is important that scientists behave based on their own sense of responsibility and ethics and care for others using a human-centered approach. Scientists should always be modest in understanding others and reflecting on themselves to recognize if a) their believed mission is not truly beneficial to all human beings or $b$ ) their research products are misused with malicious intention.

"Planetary health," which is defined as "the health of human civilisation and the state of the natural systems on which it depends" (Whitmee et al. 2015), is placed at the center of activity of international research programmes, such as Future Earth. With such broad views, science can contribute more to "Shape Peace Together" for sustainability.

Acknowledgements The author is grateful to Prof. Shinji Kaneko and his colleagues at the Network for Education and Research on Peace and Sustainability (NERPS), Hiroshima University, Japan, and Professors Hassan Virji and Paul Shrivastava, advisors to NERPS, for leading this new and timely horizon area of science and for offering an opportunity to contribute to this special issue.

\section{References}

Asayama S et al (2020) Are we ignoring a black elephant in the Anthropocene? climate change and global pandemic as the crisis in health and equality. Sustain Sci. https://doi.org/10.1007/ s11625-020-00879-7

Future Earth and Earth League (2019) 10 New Insights in Climate Science 2019. https://futureearth.org/publications/science-insights/ 10-new-insights-in-climate-science-2019/. Accessed 30 Sep 2020

IAP (2005) IAP Statement on Biosecurity. https://www.interacademies. org/statement/iap-statement-biosecurity. Accessed 30 Sep 2020

IDMC (2019) 'GRID 2019: Global Report on Internal Displacement', https://www.internal-displacement.org/publications/2019-globalreport-on-internal-displacement. Accessed 30 Sep 2020

Science Council of Japan (2012) Report on Dual Use Issue of Science and Technology (in Japanese). http://www.scj.go.jp/ja/info/kohyo/ pdf/kohyo-22-h166-1.pdf. Accessed 30 Sep 2020

Science Council of Japan (2013) Code of Conducts for Scientists Revised Version (in Japanese). http://www.scj.go.jp/ja/info/kohyo/ pdf/kohyo-22-s168-1.pdf. Accessed 30 Sep 2020

Steffen W et al (2015) The trajectory of the Anthropocene: the great acceleration. Anthr Rev 2:81-98. https://doi.org/10.1177/20530 19614564785

UN News (2020) Bolster fragile world to emerge stronger, UN chief urges, marking Peace Day. https://news.un.org/en/story/2020/09/ 1072622. Accessed 30 Sep 2020

US CDC (2020) Health Equity Considerations and Racial and Ethnic Minority Groups. https://www.cdc.gov/coronavirus/2019-ncov/ community/health-equity/race-ethnicity.html. Accessed $30 \mathrm{Sep}$ 2020

Whitmee S, Haines A, Beyrer C et al (2015) Safeguarding human health in the Anthropocene epoch: report of The Rockefeller FoundationLancet Commission on planetary health. Lancet 6736:1973-2028. https://doi.org/10.1016/S0140-6736(15)60901-1

Yoshikura H (2013) Biosecurity, dual use and research ethics. J Disaster Res 8(4):644-653

Zinn JO (2020) A monstrous threat": how a state of exception turns into a "new normal. J Risk Res. https://doi.org/10.1080/13669 877.2020 .1758194

Publisher's Note Springer Nature remains neutral with regard to jurisdictional claims in published maps and institutional affiliations. 